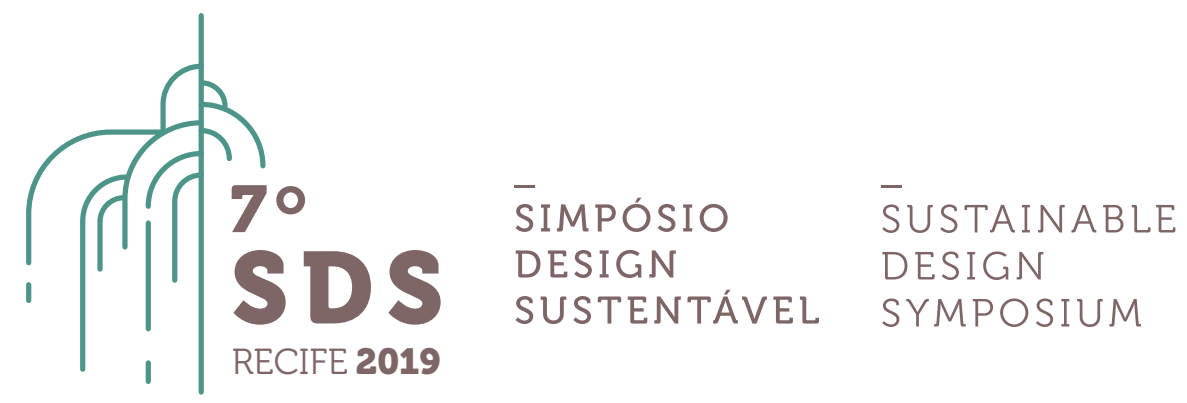

\title{
Cultura construtiva: como apreender a memória de um saber tradicional em vias de erradicação por meio do Design Participativo
}

\author{
Fabiana Aquino de Moraes Rêgo ${ }^{1}$, Maria Luiza Lopes de Oliveira Santos ${ }^{2}$ e Raquel Gomes Noronha ${ }^{3}$ \\ ${ }^{1}$ Especialista, Universidade Federal do Maranhão, fabiaquino11@hotmail.com \\ ${ }^{2}$ PhD, Universidade Federal do Maranhão, mllo.santos@ufma.br \\ ${ }^{3}$ Doutora, Universidade Federal do Maranhão, raquel.noronha@ufma.br
}

\begin{abstract}
Resumo. Este artigo trata de questões acerca do tema Cultura construtiva: como apreender a memória de um saber tradicional em vias de erradicação por meio do Design Participativo, dentro da complexa correlação de políticas e ações externas que supõe promover o desenvolvimento em comunidades rurais $e$ quilombolas. Ações que podem levar ao processo de erradicação de um saberfazer construtivo tradicional passado de geração para geração e que transmite cultura e memória. Seu contorno está delineado a partir de uma série de reflexões teórico-conceituais obtidas através de uma revisão literária a priori explanatória e que tem como principal foco a metodologia do Design Participativo com aproximação de áreas que contribuem para a valorização de um saber tradicional, que nesse caso trata-se de uma cultura construtiva. Portanto o artigo em questão caracteriza-se como de revisão a partir de textos relevantes para o Design. Para isso utilizou-se conceitos discutidos por Clay Spinuzzi, Tim Ingold, Raquel Gomes Noronha, Chiara del Gaudio, dentre outros.
\end{abstract}

Palavras-chave. Memória; Cultura construtiva; Design Participativo.

\section{Introdução}

As comunidades rurais e quilombolas existentes pelo Brasil a fora têm sido submetidas a políticas e ações externas que implicam mudanças nas relações desses grupos sociais com a moradia em que habitam e que em boa parte foram produzidas por eles mesmos, às vezes ao longo de gerações. A produção desses lares foi tecida ao longo do tempo dando origem a uma cultura construtiva e a um saber tradicional que envolve recursos da biodiversidade, modos de fazer tradicionais, costumes e também hábitos de consumo.

Diante disso, a devastação de comunidades inteiras com grandes e súbitos projetos de transformação (leia-se "desenvolvimento") como foi o caso da implantação e expansão do Centro de Lançamento de Alcântara (CLA) vem afetando, desestruturando e deslocando inúmeras comunidades para agrovilas ou para outras áreas e, impondo um método construtivo racionalista 
diferente da forma espontânea e dinâmica de construir das comunidades que foi herdada de países africanos e tecida ao longo do tempo, ferindo a cultura construtiva das pessoas que ali residem. Tais fatos vêm promovendo a utilização por parte dos quilombolas de materiais construtivos como tijolos e telhas cerâmicas de queima em detrimento do adobe e da palhoça, apesar dos últimos se tratarem de materiais mais baratos e mais acessíveis às comunidades.

Devido às imposições das ações externas por quem detém o poder, em muitas dessas comunidades está em curso a substituição de moradias feitas com técnicas construtivas tradicionais - como pau a pique e adobe - por moradias de tijolo cerâmico produzidas com técnicas convencionais de construção. Está postura ocasiona o progressivo desaparecimento de um saber-fazer construtivo tradicional passado de geração para geração e que transmite cultura e memória, em prol de uma outra ideia de desenvolvimento.

Por essa razão, este artigo pretende abordar a apreensão da memória de uma cultura construtiva tradicional por meio do Design Participativo, em comunidades rurais e remanescentes de quilombo localizadas no município de Alcântara - MA. Diante desse cenário de provável erradicação de um saber tradicional e, consequentemente do desaparecimento de um contexto de relações socioespaciais e socioambientais encontramos motivação para conhecer algumas dessas comunidades em questão.

A apreensão da memória de um saber tradicional e consequentemente a sua preservação como técnica construtiva tradicional se dará através da formatação de um trabalho bibliográfico contendo o registro da mesma com uso de imagens e de informações obtidas nos discursos dos quilombolas, detentores desse saber fazer construtivo. Os relatos e discursos a serem obtidos nesta pesquisa nos conduzirá no campo, tanto possibilitando a aproximação com os atores sociais envolvidos, quanto estimulando estes atores na construção dos seus discursos e na apreensão das suas memórias.

Neste contexto tivemos a oportunidade de realizar uma breve visita de campo durante um fim de semana em algumas comunidades rurais e quilombolas do município de Alcântara/MA. A visita confirmou a suspeita de que muitas comunidades já quase não produzem suas moradias com terra crua, o quê nos fez comprovar o risco de erradicação da memória construtiva desses vilarejos em questão. A presença de casas de alvenaria de tijolo cerâmico tornou-se uma constante por onde passamos. As poucas casas de pau a pique e adobe foram vistas de forma isolada e, mas precisamente afastadas dos núcleos centrais dos vilarejos.

A experiência de poucos dias nos deixou ávidas por conhecer mais profundamente o campo que pensamos trabalhar em pesquisas futuras. Mas naquele momento o objetivo era o de meramente conhecer superficialmente e observar as moradias dos lugares que visitamos. Muitos questionamentos surgiram a partir desse primeiro contato, sobretudo quanto ao fato do provável desaparecimento de saberes tradicionais e o distanciamento progressivo das comunidades com a sua memória construtiva. Daí nos ocorreu apreender a memória desses saberes através da vivência das pessoas que residem nesse tipo de moradia ou ainda daquelas que já não residem, porém as conhecem e possuem lembranças das mesmas.

Acreditamos que a apreensão da memória de um saber tradicional seja uma alternativa de preservação e valorização do território e das tradições nele presentes. Ressaltando que a cultura construtiva tradicional de uma determinada localidade é tratada nesse artigo como um saberfazer tradicional, ou seja, um conhecimento empírico, informal e espontâneo que nasce e vive nestas comunidades, porém que infelizmente encontra-se deteriorado em vias de se perder. É um "saber" nascido de uma percepção sensorial e de um engajamento prático adquirido pela vasta experiência de vida com o material, a terra. 
Construir com as técnicas construtivas tradicionais remete ao processo que envolve o saber, o fazer e os materiais em processo de elaboração; as qualidades da matéria-prima, a umidade do ambiente, o clima e as estações do ano. Outro ponto de vista que a valorização e a preservação também sugerem é a manutenção das famílias em sua comunidade evitando deslocamentos e o risco de falência do território, assim como o desaparecimento de grupos étnicos que os compõem.

Cabe mencionar de antemão que o artigo em questão caracteriza-se como artigo de revisão onde, resumidamente a metodologia que utilizamos é primordialmente uma revisão de literatura a priori explanatória que tem como principal foco o questionamento acerca de "como apreender a memória de uma cultura construtiva tradicional em vias de erradicação por meio do Design Participativo". Para tanto buscamos autores que têm destaque com relação a cada tema explanado.

Inicia-se com reflexões acerca da apreensão da memória e o temor da erradicação e para tanto lançamos mão das obras; "A memória coletiva" do autor Maurice Halbwachs que em sua obra destaca - dentre outras abordagens - a distinção entre lembrança e memória, a concepção de memória coletiva, a relação entre memória coletiva e o espaço, e por último a relação entre memória coletiva e o tempo. E também da obra "Memórias do social" do autor Henri-Pierre Jeudy.

Em seguida, reconhecemos as qualidades e os valores da cultura construtiva tradicional entendida como um saber tradicional que resulta em um produto, que nesse caso são as casas produzidas com terra crua que representam o patrimônio construído e a identidade dos territórios. Os alicerces para desenvolver esse item foram um capítulo da obra "Estar vivo: ensaios sobre movimento, conhecimento e descrição" do antropólogo Tim Ingold e um capítulo do livro "An unfinished compendium of materials" escrito por Rachel Harkness no qual a autora descreve um evento que ocorreu em 2015 em um centro de construção em terra da Escócia.

Por fim, temos a oportunidade de discorrer sobre o Design Participativo, tanto como metodologia quanto como abordagem, explanando sua definição, novos contextos de atuação e desafios. As obras referenciadas são artigos da designer e antropóloga Raquel Noronha, do também antropólogo Tim Ingold, da designer Chiara del Gaudio et al e do professor de retórica e redação Clay Spinuzzi.

\section{A apreensão da memória e o temor da erradicação}

Como forma de apreender a memória de um saber tradicional em vias de erradicação destacamos a distinção entre lembrança e memória, a concepção de memória coletiva, a relação entre memória coletiva e o espaço, e por último a relação entre memória coletiva e o tempo.

A lembrança é um processo coletivo inserido em um contexto social dependente de um grupo que estabelece relações sociais entre seus indivíduos e que, por conseguinte, gera afetos entre os mesmos. Esse apego afetivo dá consistência às lembranças enquanto que o desapego está relacionado ao esquecimento e à indiferença.

Sentimento de algo que já foi visto e/ou vivido, para Halbwachs (2004) a lembrança é reconhecimento e reconstrução. É reconhecimento no sentido que adota o "já visto" e é reconstrução ao não ser uma repetição de acontecimentos e vivências do passado, e sim um resgate desses acontecimentos e vivências em um contexto de interesses e preocupações atuais, localizado em um espaço, em um tempo e em um conjunto de relações sociais.

A necessidade de uma comunidade afetiva, ou seja, a dependência pela existência de um grupo social que gere relações de afeto faz com que as lembranças não sejam simplesmente ideias 
ou sentimentos individuais e isolados. Portanto concluímos que uma memória estritamente individual faz-se difícil, visto que as lembranças são construídas e articuladas a partir da relação de pertencimento do indivíduo com um grupo.

A localização das lembranças em um determinado espaço e tempo é o que a distingue do fluxo contínuo e passageiro das vivências. É nesse contexto que a articulação das lembranças entre si concebe a natureza coletiva da memória. Para Halbwachs (2004) a construção da memória é sempre em grupo, porque em realidade nunca estamos sós. Segundo o autor ainda que o indivíduo esteja sozinho fisicamente, ele evocará reflexões e pensamentos baseados em outros grupos ou outras pessoas de referência, com os quais se identifica.

Uma das formas de apreender essas memórias coletivas é por meio do Design Participativo, ou seja, uma metodologia que almeja uma compreensão aprofundada de hábitos e dinâmicas de um grupo social que experimentou ou ainda experimenta em comum a realidade de uma cultura construtiva tradicional em vias de erradicação. Ao avaliar essas vivências e testemunhos, poderemos encontrar algumas divergências, mas ainda sim conseguiremos reconstruir um conjunto de lembranças de modo a reconhecer uma realidade vivida.

A concepção da memória coletiva e de sua apreensão deve ser conquistada junto a esses testemunhos, ou seja, lembranças articuladas de pessoas que residem na comunidade e que possivelmente já possuem uma idade avançada. Para Jeudy (1990) a memória coletiva é trabalhada em meio à ameaça de seu próprio desaparecimento. Uma quantidade singular de traços pode ser preservada, ainda mais quando os últimos representantes da época apaixonam-se pela reconstituição da sua própria vida social e cultural.

Para isso é importante compreender a especificidade e a singularidade das pessoas que compõem esses grupos sociais em diferentes épocas, pois tempo localiza as lembranças que a partir dele "toma corpo e se completa" (HALBAWACHS, 2004). A relevância do tempo consiste em nos permitir conservar e lembrar dos acontecimentos passados que ali se produziram e, também recordar lembranças vividas. Maurice Halbawachs, autor do livro A memória coletiva afirma que esse é o serviço que esperamos do tempo, "enquadrar as lembranças".

\footnotetext{
Quando nos lembramos de uma viagem, mesmo não nos lembrando da data exata, há entretanto todo um quadro de dados temporais aos quais essa lembrança está de qualquer maneira relacionada: foi antes ou depois da guerra, eu era criança, jovem, ou homem feito, na pujança da idade; eu estava com tal amigo que me era mais ou menos velho; em que estação estávamos; eu preparava tal trabalho; aconteceu tal coisa. É graças a uma série de reflexões desse gênero que com muita frequência uma lembrança toma corpo e se completa (HALBAWACHS, 2004, p. 106).
}

Assim como o tempo, o quadro espacial também contribui para localizar as lembranças. A memória em relação ao espaço nos oferece - diferentemente em relação ao tempo - a noção de estabilidade e permanência, e nos lembramos de costumes de outrora, recordando pessoas e relações sociais ligadas a esse espaço em questão.

Desta forma um lugar é moldado por um grupo e por outro lado este tende a deixar marcas em um determinado local. Como explica Halbwachs (2004) as coisas que nos cercam têm um sentido que deciframos familiarmente. Talvez por isso estabelecemos relações de pertencimento com o nosso território e com nossas moradias. Apegamos-nos a elas e ao espaço onde convivemos e muitas vezes desejamos que não mudem.

A aderência do grupo ao seu local de origem produz resistência e ressentimentos quando esse mesmo grupo é deslocado ou afastado do seu território. Quando isso acontece os indivíduos perdem traços de si mesmos. Cada grupo recorta o território a seu modo, constituindo um quadro fixo onde encerra e localiza suas lembranças. 
Também os objetos materiais que fazem parte do nosso quadro espacial pouco mudam ou mudam lentamente em nosso contato diário com eles e por isso nos passam a ideia de ordem e quietude ou permanência e estabilidade como já foi mencionado. Halbwachs (2004) diz ainda que a estabilidade do alojamento e de seu aspecto interior impõe ao próprio grupo a imagem apaziguante de sua continuidade.

O temor da erradicação da cultura construtiva tradicional em comunidades rurais e remanescentes de quilombo em Alcântara/MA clama por uma alternativa. Em nome da inovação tecnológica e do desenvolvimento, práticas e valores tendem a ser erradicados e a desaparecerem dessas sociedades. Com isso, a comunidade perde sua identidade e sua cultura.

Esse temor também coloca o patrimônio construído tradicionalmente em perigo alertando sobre a apreensão das memórias coletivas como forma de reconstruir uma prática construtiva (um saber tradicional) que existiu, fazendo-se necessário preservá-la e não deixá-la no compartimento do esquecimento.

A memória coletiva pode redefinir, requalificar e reinventar um passado que o tempo erradicou e se não fora assim, esse passado poderia morrer definitivamente e permanecer desconhecido para muitas pessoas.

\section{A cultura construtiva entendida como um saber tradicional}

O termo "cultura construtiva" pode ser considerado originado de processos produtivos de um grupo social ou de uma comunidade em um território específico. É usado correntemente no Brasil para designar as moradias feitas com terra. Na maioria das vezes essas moradias são consideradas precárias, possuindo uma conotação de pobreza. No entanto cabe lembrar que os modos de construção que Ihe são associados historicamente não corroboram com essa imagem negativa.

Ao construir com a terra, os construtores estão transformando um material onipresente e muitas vezes denegrido em algo valorizado, e o fazem de maneira apropriada ao seu lugar, habilidades, necessidades e tempo. Seu conhecimento sobre a terra, de origem local, como um eco-material adequado para uso generalizado em um mundo onde a dependência de combustíveis fósseis e cimento, concreto, aço, vidro e até madeira é extremamente prejudicial, às vezes os ajuda em sua recuperação associada à privação ou pobreza (HARKNESS, 2017, p. 66).

A terra crua como matéria prima disponível no meio ambiente natural torna-se assim a identidade de um grupo social e parte de sua história produtiva, onde passa por inúmeras transformações repetidamente e desenvolvimento até atingir sua finalidade como "produto final" que consiste primordialmente nas moradias das famílias que residem nessas comunidades. Harkness (2017) cita que a terra tem sido trabalhada com frequência por várias gerações e pode ser parte de um futuro ambientalmente consciente. Como prática, a construção em terra é historicamente enraizada e orientada para o futuro, conclui Harkness.

As reflexões aqui expostas acerca das culturas construtivas tradicionais não dizem respeito às tipologias construtivas ou descrições técnicas das mesmas, mas sim estão voltadas para a percepção das mesmas como saberes e fazeres tradicionais que são passados de geração para geração, transmitindo cultura e memória.

Neste contexto a cultura construtiva em terra é entendida como saberes tradicionais produzidos na própria comunidade onde buscam o "fazer" de forma tácita, coletiva, sustentável e participativa. A partir do uso de uma serie de materiais e recursos disponíveis no local e nas 
proximidades do território. Segundo INGOLD (2015) o conhecimento vem da experiência de uma vida de trabalho com o material. Esse é um conhecimento nascido da percepção sensorial e do engajamento prático.

Semelhante ao que ocorre no saber-fazer tradicional, essas comunidades produziram "processos" em diferentes momentos da história social e conseguiram reproduzi-los e transmitilos ao longo do tempo, através de sucessivas gerações. Para Noronha (2018) o que é transmitido pela oralidade e reafirmado pela manualidade é o que caracteriza o conhecimento artesanal. Para muitos esse saber-fazer é considerado especializado e respeitado, pois além de revigorar territórios, fortalece a autonomia comunitária, seja de forma espacial, social ou política.

Já o papel da temporalidade da cultura construtiva tradicional emerge como uma pista para o entendimento de sua natureza. O tempo da construção, diferente do tempo da indústria, revela o saber fazer que é transmitido pela oralidade, que demora a ser produzido, que depende de condições climáticas, que remete a outro tempo - o tempo da narrativa.

Por outro lado a nossa interpretação a respeito do relativo desprezo por um saber tradicional do qual muitos dependeram por tanto tempo é correlata ao repúdio pelo material utilizado - a terra crua - devido dentre outros motivos, à ideia imposta de promover o desenvolvimento econômico e social associado às moradias construídas com técnicas convencionais como alvenaria de tijolo cerâmico. Além da conotação de pobreza mencionada acima, a mudança dos jovens para os centros urbanos, faz também com que as técnicas construtivas com adobe e pau a pique desapareçam.

Essa suposta construção equivocada do desenvolvimento econômico e social provém de politicas impostas a que as comunidades inevitavelmente estão sujeitas e cujo ideário tendem cada vez mais a incorporar. Está muito mais relacionado a motivações simbólicas da comunidade e a ações do Estado do que à razoes técnicas ou materiais. As mudanças decorrentes das imposições políticas raramente resultam de decisões conscientes tomadas pela própria comunidade.

Segundo Kapp (2016) em vez de estimular a apropriação criativa de uma tecnologia a partir de conhecimentos e condições existentes, ações externas paralisam iniciativas locais e ainda desvalorizam e até invalidam práticas tradicionais. A fim de não erradicar modos de vida instituídos devemos procurar soluções que aumentem as possibilidades e valorize à transmissão de saberes. Soluções estas que passem pela preservação da cultura local e pela percepção de pertencimento do lugar de viver e morar. Por meio do design participativo acreditamos que há caminhos possíveis.

O envolvimento do grupo social - pessoas que residem na comunidade - de forma participativa, nesse caso pode ser considerado a base para a compreensão sobre esse material; a terra, assim como sobre esse saber tradicional. O entendimento aqui diz respeito não somente as propriedades objetivas e mensuráveis do material, mas também a expressão das suas qualidades subjetivas através dos discursos.

Em suma, para INGOLD (2015) "as propriedades dos materiais, não são atributos, mas histórias", pois segundo ele o material pode ser analisado pela sua significância que é extraída de sua incorporação no contexto das questões humanas. Para tanto se faz imprescindível compreender as relações e as experiências das comunidades rurais com as moradias que usam e produzem para empreender ações de melhoria das suas condições de vida. Também é importante levantarmos dados e informações acerca das dificuldades e conflitos que as comunidades em locais de difícil acesso enfrentam.

Essa reflexão deixa claro a importância e o status da ação na realização da experiência operatória, memorizada e transmitida. Uma cultura construtiva, encarada como um saber-fazer 
tradicional produz seus espaços baseados em uma integração estreita com o seu meio ambiente natural, sua história e seu material.

Aprenderíamos mais envolvendo-nos diretamente com os próprios materiais, seguindo o que acontece com eles quando circulam, misturam-se uns aos outros, solidificam-se e se dissolvem na formação de coisas mais ou menos duráveis (INGOLD, 2015).

\section{Por meio do Design Participativo}

Como forma de entender as percepções e respostas acerca de um saber tradicional em vias de erradicação foi lançado mão da definição e dos desafios do Design Participativo, como metodologia e como abordagem, considerando seus novos contextos de atuação. No artigo "The methodology of the Participatory Design", Spinuzzi (2005) discute o Design Participativo como uma metodologia de pesquisa, caracterizando-o como uma maneira de entender o conhecimento fazendo, de forma tradicional, tácita e muitas vezes invisível.

A pesquisa apoiada nessa metodologia requer abolir hierarquias, pensar e atuar no coletivo. Considerar o território em questão, seus costumes, modos de vida, expectativas e tecnologias. Segundo Noronha (2018), dirimir as hierarquias e homogeneizações provocadas pela própria ideia de ciência é o maior desafio do codesign.

No entanto nem sempre é fácil explicar metodologicamente o design participativo e, talvez por isso frequentemente pensamos no mesmo somente como uma abordagem ao design caracterizada pelo envolvimento do antes "usuário" e agora atuais atores sociais que assumem o papel de codesigners na "promoção de sentidos para os problemas de sua própria existência no mundo" (NORONHA, 2018, p. 127).

O preceito do design participativo consiste em garantir que os posicionamentos e interpretações dos participantes sejam relevantes na pesquisa ou no projeto. Leva-se em conta o conhecimento tácito e informal dos grupos sociais envolvidos na mesma, assim como os aspectos invisíveis da atividade humana no seu cotidiano. O conhecimento, nesse caso são práticas e interações, interpretativas difíceis de serem descritas e formalizadas. Como indica SPINUZZI (2005):

\footnotetext{
Quando pensamos em conhecimento, frequentemente pensamos em formas explícitas de conhecimento; coisas que são escritas, definidas, categorizadas, sistematizadas ou quantificadas. Mas, para entender a criação de conhecimento no design participativo, temos que entender que muito conhecimento tende a ser tácito. $\mathrm{O}$ conhecimento tácito é implícito e não explícito, holístico, em vez de limitado e sistematizado; é o que as pessoas sabem sem ser capazes de articular (SPINUZZI, 2005, p. 167, tradução nossa).
}

Um dos objetivos do Design Participativo no que diz respeito ao artigo é compreender as relações das comunidades rurais e quilombolas com suas moradias feitas de terra, resultantes de um saber tradicional passado de geração para geração, porém que se encontra em vias de desaparecimento. Resumidamente, o objetivo principal consiste em preservar e valorizar esse conhecimento tácito. De forma mais abrangente promove a autoestima, o reconhecimento e a valorização da identidade cultural de grupos sociais vulneráveis.

Pretendemos acionar, por meio do Design Participativo, discursos e relatos referentes a execução da técnica construtiva tradicional, observar e registrar as etapas de trabalho que envolvem as técnicas e, por fim interpretar o valor atribuído à mesma e ao material pelos quilombolas. 
$\mathrm{Na}$ metodologia do Design Participativo, o designer assume o papel de mediador e facilitador, mas para tanto deve chegar a conclusões em conjunto com os atores sociais envolvidos na pesquisa. Embora seja uma metodologia que ainda está se desenvolvendo, alguns métodos são comumente utilizados em quase todas as pesquisas. Dentre esses métodos, a observação participante assume um papel relevante e também supostamente contraditório. Ingold (2016) explica que observar significa ver o que acontece no entorno e, é claro, também ouvir e sentir. Participar significa fazê-lo a partir de dentro da corrente de atividades através da qual a vida transcorre, concomitante e conjuntamente com as pessoas e coisas que capturam a atenção que se dispensa a elas.

Essa suposta contradição entre observação e participação se desvanece na habilidade de perceber e na capacidade de julgar durante o envolvimento direto, profundo, prático e sensível aquilo que está à nossa volta. A observação participante depende de muitas circunstâncias, como também do tempo e do local, e não avança em direção a um fim preestabelecido. Lida com pessoas que de acordo com INGOLD (2016) "reconhecem o passado, atentam para as condições do presente e se abrem especulativamente a possibilidades futuras".

Em se tratando de uma abordagem, o design participativo visa à inovação social onde considera fundamental os atores sociais, sua participação, habilidades e conhecimento do contexto. Segundo GAUDIO (2014) nos últimos anos numerosos estudos têm apontado para potencialidades de processos co-criativos e participativos de design que pretendem contribuir na resolução de questões sociais e na melhoria do contexto de vida cotidiano da população envolvida. E vale ressaltar que no design participativo, os atores sociais refletem criticamente sobre suas próprias práticas.

O termo "inovação Social" refere-se a soluções multidisciplinares e flexíveis capazes de ir além dos limites institucionais, de gerar mudanças duradouras e de melhorar problemas sociais amplos (GAUDIO, 2014). As inovações no design participativo são soluções efetuadas pelas próprias pessoas participantes e residentes na comunidade em questão a fim de responder as necessidades básicas e cotidianas que podem produzir mudanças significativas no grupo social local.

Além dos participantes, o local e o tempo são aspectos contextuais determinantes nesse tipo de abordagem. Frequentemente atua-se em comunidades marginalizadas e socialmente vulneráveis como no caso onde pretendemos trabalhar, ou seja, em comunidades rurais de difícil acesso e remanescente de quilombo. E no caso específico das comunidades remanescentes de quilombo em Alcântara, esses espaços vêm sendo transformados em razão de interesses políticos a partir de uma lógica intervencionista que diz respeito à instalação de um grande projeto desenvolvimentista de caráter tecnológico e militar em seus territórios, o Centro de Lançamento de Alcântara (CLA).

Diante desse contexto do local, o pesquisador-designer tem que estar preparado para as dinâmicas de vida - que regulam os relacionamentos, as colaborações, as atividades - que vai encontrar e se confrontar. Muitas vezes, bem diferente do seu próprio contexto, com grandes contrastes culturais e estilos de vida.

Sobre o tempo GAUDIO (2014) o considera objetivamente, ou seja, o tempo efetivamente à disposição em termos de números de horas e organização da agenda e, subjetivamente onde a percepção do tempo pelos diversos atores envolvidos e a necessidade de tempos diversos para um desenvolvimento proveitoso. Tanto para Gaudio (2014) como para Ingold (2016) o tempo no design participativo é chave e requer uma atenção especial por parte dos designerspesquisadores. A observação participante envolve muita espera, conclui Ingold (2016). 
Sendo assim, a metodologia do trabalho terá como base a seleção das comunidades quilombolas, cujos critérios serão as comunidades mais antigas e mais isoladas geograficamente do centro urbano de Alcântara/MA; serão realizadas visitas para coleta in loco de informações, através de registros de imagens e relatos dos quilombolas no que tange a prática do saber fazer construtivo; após a obtenção das informações, haverá a análise e formatação do documento bibliográfico.

\section{Considerações finais}

Consideramos que a partir da pesquisa de caráter bibliográfico foi possível abordar a temática de como apreender a memória de uma cultura construtiva tradicional em vias de erradicação por meio do design participativo. Nesse contexto, evidenciou-se o papel e a importância da memória como forma de resgatar e preservar "saberes tradicionais". O pragmatismo das técnicas construtivas tradicionais demonstrou que o homem acumulou o saber empírico herdado de gerações de artesãos, mestres e artífices, porém que se desvanece com o provável desaparecimento desse saber fazer integrado, acumulado e transmitido de geração em geração.

Para tanto, propomos convergir as estratégias de apreensão dessa memória rompendo com metodologias convencionais e assumindo o design participativo como abordagem e como metodologia de pesquisa de campo a fim de compreender os discursos e as práticas dessas comunidades no que diz respeito à saberes tradicionais que deram, e que até hoje dão origem, às suas moradias por meio do fazer manual.

Nós, como co-pesquisadores e designers nos tornamos tradutores e mediadores de processos sociais e culturais, nos quais precisamos compreender as experiências sensoriais e psicológicas sobre a cultura construtiva e o processo de globalização que podem interferir nos meios de produção da mesma. Devemos problematizar a própria necessidade de moradia, a desvalorização e a substituição de técnicas construtivas tradicionais por técnicas construtivas convencionais e, consequentemente a substituição de materiais utilizados.

Concluímos que a cultura construtiva tradicional se lastreia não somente na capacidade de atender à sua função de produzir moradias, mas também na sua dimensão simbólica. Nessa ressignificação o que realmente interessa é a capacidade de técnicas e práticas aportarem valores que vêm sendo cada vez mais reconhecidos recentemente, tais como singularidade e pertencimento, transmitindo cultura e memória.

Essa memória da cultura construtiva que almejamos apreender favorece a valorização e preservação da cultura de um grupo social étnico-racial e o laço afetivo que o envolve com o lugar. Em tantas comunidades quilombolas espalhadas pelo estado do Maranhão - mais precisamente no município de Alcântara - que concentra um terço das comunidades remanescentes de quilombos do estado em apenas um município, iniciativas marcadas pelo Design Participativo podem evitar o desaparecimento de um contexto de relações sócio-espaciais e socioambientais, além de trazer um novo impulso ao desenvolvimento sustentável local.

E para finalizar, consideramos por bem enfatizar a importância da preservação e da valorização do território e das tradições nele presentes diante da iminência da erradicação de saberes tradicionais por meio do Design Participativo. Torna-nos um pesquisador-designer participante conjuntamente com a comunidade é crucial para promover o desenvolvimento do território e garantir a perpetuação das técnicas, mesmo que propondo melhorias. Para tanto as técnicas empregadas devem considerar o território, os recursos utilizados e especialmente, a comunidade que as utiliza. 
Por fim, ressalta-se que o desenvolvimento do trabalho em tela promoverá efetivamente a preservação da técnica construtiva tradicional por meio do Design Participativo fazendo com que essa cultura construtiva não se perca no tempo e possa se tornar acessível às futuras gerações, principalmente aos descendentes quilombolas.

\section{Referências}

GAUDIO, Chiara del, OLIVEIRA, Alfredo Jefferson de, FRANZATO, Carlo. O tempo do Design Participativo. In: 11을 Design. Congresso Brasileiro de Pesquisa e desenvolvimento em Design, n. 4, v. 1, 2014, Gramado. Metodologias e Processos de Design. Co-design, design participativo e design colaborativo. São Paulo: Blucher Design Proceedings, 2014. p. 1-13.

HALBWACHS, Maurice. A memória coletiva. Tradução de Laís Teles Benoir. São Paulo: Centauro, 2044.

HARKNESS, Rachel. Earth. Clayfest and The Dreaming Grounds. In: (org.). An Unfinished Compendium of Materials. Aberdeen: University of Aberdeen, 2017. p. 64-71.

INGOLD Tim. Materiais contra materialidade. In: Estar vivo. Ensaios sobre movimento, conhecimento e descrição. Petrópolis: Editora Vozes, 2015. Parte II, p. 49-69.

INGOLD Tim. Chega de etnografia! A educação da atenção como propósito da antropologia. In: Revista Educação, n. 3, v. 39, 2016. Porto Alegre: Pontifícia Universidade Católica do Rio Grande do Sul, 2016. p. 404 - 411.

JEUDY, Henri-Pierre. Memórias do social. Tradução de Márcia Cavalcanti. Rio de Janeiro: Forense Universitária, 1990.

KAPP, Silke. Levantamento sócio-espacial: um método num vilarejo. In: Revista Paranoá. Cadernos de Arquitetura e Urbanismo, n. 17, 2016, Brasília. Habitat no Campo, nas Aguas e nas Florestas. III Colóquio Habitat e Cidadania: Habitação nos Campos, nas Aguas e nas Florestas. Brasília: Universidade de Brasília (UNB), 2016.

NORONHA, Gomes Raquel. The collaborative turn: Challenges and limits on the construction of a common plan and on autonomía in design. In: Strategic Design Research Journal, n. 2, 2018. Autonomía - Design strategies for enabling design process. São Leopoldo: Universidade do Vale do Rio dos Sinos - UNISINOS, 2018. p. 125-135.

PATROCÍNIO, Gabriel. Design e os países em desenvolvimento: a dialética entre o design para a necessidade e o design para o desenvolvimento. Gabriel Patrocínio e José Mauro Nunes (Org.). Design \& Desenvolvimento: 40 anos depois. São Paulo: Blucher, 2015. p. 55-74.

SPINUZZI, Clay. The methodology of the Participatory Design. In: Technical Communication, n. 2, v. 52, p. 163-174, maio 2005. 